\title{
Gaseous air pollution and emergency hospital visits for hypertension in Beijing, China: a time- stratified case-crossover study
}

\author{
Yuming Guo ${ }^{1 *}$, Shilu Tong ${ }^{1}$, Shanshan Li $^{2}$, Adrian G Barnett ${ }^{1}$, Weiwei Yu', Yanshen Zhang ${ }^{3}$, Xiaochuan Pan ${ }^{4 *}$
}

\begin{abstract}
Background: A number of epidemiological studies have been conducted to research the adverse effects of air pollution on mortality and morbidity. Hypertension is the most important risk factor for cardiovascular mortality. However, few previous studies have examined the relationship between gaseous air pollution and morbidity for hypertension.

Methods: Daily data on emergency hospital visits (EHVs) for hypertension were collected from the Peking University Third Hospital. Daily data on gaseous air pollutants (sulfur dioxide $\left(\mathrm{SO}_{2}\right)$ and nitrogen dioxide $\left(\mathrm{NO}_{2}\right)$ ) and particulate matter less than $10 \mu \mathrm{m}$ in aerodynamic diameter $\left(\mathrm{PM}_{10}\right)$ were collected from the Beijing Municipal Environmental Monitoring Center. A time-stratified case-crossover design was conducted to evaluate the relationship between urban gaseous air pollution and EHVs for hypertension. Temperature and relative humidity were controlled for.
\end{abstract}

Results: In the single air pollutant models, a $10 \mu \mathrm{g} / \mathrm{m}^{3}$ increase in $\mathrm{SO}_{2}$ and $\mathrm{NO}_{2}$ were significantly associated with EHVs for hypertension. The odds ratios (ORs) were 1.037 (95\% confidence interval (Cl): 1.004-1.071) for $\mathrm{SO}_{2}$ at lag 0 day, and 1.101 (95\% Cl: 1.038-1.168) for $\mathrm{NO}_{2}$ at lag 3 day. After controlling for $\mathrm{PM}_{10}$, the ORs associated with $\mathrm{SO}_{2}$ and $\mathrm{NO}_{2}$ were 1.025 (95\% Cl: 0.987-1.065) and 1.114 (95\% Cl: 1.037-1.195), respectively.

Conclusion: Elevated urban gaseous air pollution was associated with increased EHVs for hypertension in Beijing, China.

\section{Background}

Numerous recent studies have assessed the adverse effects of air pollution on population health, including mortality, hospital admissions, and emergency hospital visits (EHVs) for cardiovascular diseases, respiratory diseases, and other diseases [1-4]. Some studies found an elevated level of ambient air pollution increased the risks of mortality and morbidity [5,6], while others found inconsistent results [7]. Also, many studies focused on the relationship between ambient air pollution and subgroups of cardiovascular diseases such as

\footnotetext{
* Correspondence: ymguo@yahoo.cn; xcpan@hsc.pku.edu.cn

${ }^{1}$ School of Public Health and Institute of Health and Biomedical Innovation, Queensland University of Technology, Kelvin Grove, Brisbane, Queensland 4059, Australia

${ }^{4}$ Department of Occupational and Environmental Health, Peking University School of Public Health, Beijing 100191, PR China

Full list of author information is available at the end of the article
}

coronary disease $[2,8]$, arrhythmia [5,9], myocardial infarction [10], and heart failure [11,12]. Our previous studies found a positive association between particulate air pollution and EHVs for hypertension and cardiovascular diseases $[1,13]$. However, less evidence is available to illustrate the effect of gaseous air pollution on acute events for hypertension.

Hypertension is not only one of the most serious risk factors for deaths and disease worldwide [14], but is also a major contributor to chronic heart failure, and a major risk factor for stroke and coronary heart disease, and their progression [15]. In the United States, the number of deaths caused by hypertension rose by $53 \%$ from 1991 to 2001 [16]. Ninety-one percent of people with heart failure had preceding hypertension, and half of all patients suffering a heart attack (and two-thirds of those having a first time stroke) have a blood pressure greater than systolic blood pressure (SBP) $140 \mathrm{mmHg}$ 
and diastolic blood pressure (DBP) $90 \mathrm{mmHg}$ [16]. Research conducted in Beijing, China shows that about $47 \%$ of investigated people had hypertension [17]. It is important to identify triggers and/or risk factors for hypertension. Air pollution may induce hypertension, so it is necessary to examine the relationship between air pollution and hypertension.

A few studies have examined the relationship between gaseous air pollution and blood pressure. Ibald-Mulli et al. [18] carried out a study using a random population sample to assess the association between air pollution and blood pressure, and found that an increase of $80 \mu \mathrm{g} /$ $\mathrm{m}^{3}$ in $\mathrm{SO}_{2}$ was linked with an increase in SBP of 0.74 mmHg (95\% CI: 0.08-1.40). De Paula Santos et al. [19] found $\mathrm{SO}_{2}$ had positive and statistically significant effects on blood pressure. $\mathrm{SO}_{2}$ was associated with blood pressure in cold weather, as well as $\mathrm{NO}_{2}$ in warm weather [20]. In addition, $\mathrm{SO}_{2}$ and $\mathrm{NO}_{2}$ also strengthened the association between particulate matter less than $2.5 \mu \mathrm{m}$ in aerodynamic diameter and blood pressure [21].

In this study we used a time-stratified case-crossover design to examine the relationship between gaseous air pollution and EHVs for hypertension.

\section{Materials and methods}

\section{Data on emergency hospital visits}

Data on EHVs for hypertension were collected between Jan 1, 2007 and Dec 31, 2007 from the Peking University Third Hospital, located in the northwest of urban city of Beijing [1]. EHVs were coded according to the International Classification of Disease, tenth revision (ICD-10) for hypertension (ICD-10: I10). The primary diagnoses were used in this study. The EHVs for hypertension were diagnosed by the visits' symptoms, inquiries, and medical inspections so that we expect the misclassification rate to be relatively small. About $95 \%$ of visits for hypertension are diagnosed only with hypertension, while $5 \%$ have accompanying heart failure, myocardial infarction or other diseases. The cases in this study lived in the residential areas around the hospital or in the urban area in Beijing.

\section{Data on air pollution and weather condition}

We accessed daily data on urban sulfur dioxide $\left(\mathrm{SO}_{2}\right)$, nitrogen dioxide $\left(\mathrm{NO}_{2}\right)$, and particulate matter less than $10 \mu \mathrm{m}$ in aerodynamic diameter $\left(\mathrm{PM}_{10}\right)$ from the Beijing Municipal Environmental Monitoring Center. Air pollutants were monitored at eight fixed monitoring sites which were distributed in the urban area of Beijing. The site map was shown in our previous study [1]. Hourly pollutant data was recorded at each site, which we made into daily averages at each site and then for the whole city. If there were missing data from a monitoring station on a given day, then the values from the remaining monitors were used to calculate the average concentration.

Daily data on temperature and relative humidity for the study period were obtained from the China Meteorological Data Sharing Service System.

\section{Data analysis}

Spearman's correlation coefficients were used to evaluate the inter-relations between air pollutants and weather conditions. The time-stratified case-crossover design was used to analyse the association of gaseous air pollution and EHVs for hypertension. The case-crossover design compares the exposure in the case period when events occurred with exposures in nearby control periods to examine the differences in exposure which might explain the differences in the daily number of cases. In this study, the cases and controls were matched by day of the week to control for any weekly patterns in deaths or pollution. Controls were compared with cases using the time-stratified method with twenty-eight days strata. So the first stratum was Jan 01 to Jan 28, 2007, the second stratum was Jan 29 to Feb 25. For an EHV on Jan 31 the control days were Feb 7, 14 and 21. The case-crossover method controls for any long-term trends and seasonal patterns in hospital visits and air pollutants. Each case day had three matching control days. The model gives the odds ratio (OR) of an EHV due to an increase in air pollution. When using the case-crossover design, confounders related to individual characteristics such as age, sex, and education are inherently controlled for. Studies have demonstrated that the case-crossover gives unbiased estimates in the presence of strong seasonal confounding [22,23].

There may be a delay between exposure to pollution and onset of hypertension. To examine the hazard period of air pollution for hypertension, we used the polynomial distributed lag model to evaluate the possibly delayed effect of air pollutants [24]. The polynomial smoothing with four degrees of freedom for $\mathrm{SO}_{2}$ and $\mathrm{NO}_{2}$ was used in the models. The hazard period was defined the same day as the hospital visit to up to five days prior.

Daily data on temperature and relative humidity were included in all models as confounders [25], using the same polynomial spline as $\mathrm{SO}_{2}$ and $\mathrm{NO}_{2}$. Single pollutant and multiple pollutants models were used to control the influence of other air pollutants. ORs and confidence intervals (CIs) were calculated for each air pollutant. All statistical tests were two-sided. The "season" package of $\mathrm{R}$ (version 2.10.1) was used to fit the time-stratified case-crossover [26,27].

\section{Results}

There were 1,491 EHVs for hypertension in Peking University Third Hospital during the study period. The 
descriptive statistics for air pollutants and weather conditions are shown in Table 1 . The average concentrations of $\mathrm{SO}_{2}, \mathrm{NO}_{2}$ and $\mathrm{PM}_{10}$ were $47.5 \mu \mathrm{g} / \mathrm{m}^{3}, 66.6 \mu \mathrm{g} /$ $\mathrm{m}^{3}$ and $149.3 \mu \mathrm{g} / \mathrm{m}^{3}$, respectively. The average levels of $\mathrm{NO}_{2}$ and $\mathrm{PM}_{10}$ air pollution were higher than the national secondary ambient air quality standard in China $\left(40 \mu \mathrm{g} / \mathrm{m}^{3}\right.$ and $\left.100 \mu \mathrm{g} / \mathrm{m}^{3}\right)$. The average concentration of $\mathrm{SO}_{2}$ was lower than the national secondary ambient air quality standard in China $\left(60 \mu \mathrm{g} / \mathrm{m}^{3}\right)$. The average temperature and relative humidity were $14.1^{\circ} \mathrm{C}$ and $54.2 \%$, respectively.

Figure 1 shows the time series of gaseous air pollutants and EHVs for hypertension. The concentrations of both $\mathrm{SO}_{2}$ and $\mathrm{NO}_{2}$ were highest in winter. The number of EHVs for hypertension was highest in November.

Table 2 shows the correlations between air pollutants, temperature and humidity. $\mathrm{PM}_{10}, \mathrm{SO}_{2}$ and $\mathrm{NO}_{2}$ were significantly correlated with each other, e.g., between $\mathrm{SO}_{2}$ and $\mathrm{NO}_{2}(\mathrm{r}=0.65, \mathrm{P}<0.01), \mathrm{PM}_{10}$ and $\mathrm{SO}_{2}(\mathrm{r}=$ $0.46, \mathrm{P}<0.01)$, and $\mathrm{PM}_{10}$ and $\mathrm{NO}_{2}(\mathrm{r}=0.64, \mathrm{P}<0.01)$.

A $10 \mu \mathrm{g} / \mathrm{m}^{3}$ increase in $\mathrm{SO}_{2}$ was significantly associated with EHVs at lags of 0 and 2 days (Top-left of figure 2), while $\mathrm{NO}_{2}$ was significantly associated with EHVs at lags of 0, 2 and 3 days (Top-left of figure 3). According to the OR values and the $95 \%$ confidence intervals, we chose the current day and three days after exposure as the hazard period for $\mathrm{SO}_{2}$ and $\mathrm{NO}_{2}$, respectively. The ORs were 1.037 (95\% CI: 1.004-1.071) for $\mathrm{SO}_{2}$ and 1.101 (95\% CI: 1.038-1.168) for $\mathrm{NO}_{2}$ (Table 3).

The results of multiple pollutant models are shown in Figure 2, Figure 3 and Table 3. For $\mathrm{SO}_{2}$, after controlling $\mathrm{PM}_{10}, \mathrm{NO}_{2}$, or both $\mathrm{PM}_{10}$ and $\mathrm{NO}_{2}$, the ORs were no longer statistically significant and the means were lower than the single pollutant model. After adjusting for $\mathrm{PM}_{10}, \mathrm{SO}_{2}$, or both $\mathrm{SO}_{2}$ and $\mathrm{PM}_{10}$, the mean effects of $\mathrm{NO}_{2}$ at lag 3 days were higher than the single pollutant model.

\section{Discussion}

This is the first study to examine the association between gaseous air pollution and EHVs for hypertension in Beijing, China. The time-stratified case-crossover was used to examine the relationship between gaseous air pollution and EHVs for hypertension. We found that gaseous air pollution had a significant impact on the EHVs visits for hypertension. An increase of $10 \mu \mathrm{g} / \mathrm{m}^{3}$ in levels of $\mathrm{SO}_{2}$ and $\mathrm{NO}_{2}$ were associated with an increase of $3.7 \%$ (95\% CI: $0.4 \%-7.1 \%)$ and $10.1 \%(95 \%$ CI: $3.8 \%-16.8 \%)$ in EHVs for hypertension, respectively. Figure 1 illustrates that the concentrations of $\mathrm{SO}_{2}$ and $\mathrm{NO}_{2}$ were remarkably higher in winter, which may be due to the increased use of heating in winter. However, we controlled for this seasonal change using the casecrossover. The major sources of $\mathrm{SO}_{2}$ and $\mathrm{NO}_{2}$ in Beijing were heating and industrial sources. Besides, urban $\mathrm{NO}_{2}$ levels are closely related to traffic emissions [28].

In order to understand if there were any short-term delays between gaseous air pollution and hypertension, the lags of 0 to 5 days were examined in the single air pollutant models. The results show that the adverse effects of $\mathrm{SO}_{2}$ on EHVs for hypertension were statistically significant at lags of 0 and lag 2 days, while the impact of $\mathrm{NO}_{2}$ was significant at lags of 0,2 , and 3 days. In a previous study, we examined the relationship between air pollution and EHVs for cardiovascular diseases from the same hospital between 2004 and 2006 and found that after adjusting for temperature and relative humidity, the ORs for EHVs for cardiovascular diseases were 1.014 (95\% CI: 1.004-1.024) and 1.016 (95\% CI: $1.003-1.029$ ) for a $10 \mu \mathrm{g} / \mathrm{m}^{3}$ increase in levels of $\mathrm{SO}_{2}$ or $\mathrm{NO}_{2}$ at lag 0 day, respectively [1]. This study suggests that the gaseous air pollution has a lagged effect on EHVs for hypertension.

In the multiple pollutant models, the OR values of $\mathrm{SO}_{2}$ were lower than the single pollutant models, particularly after controlling for $\mathrm{NO}_{2}$. Conversely, the OR values of $\mathrm{NO}_{2}$ were higher than the single pollutant models. Previous research [1,29] on the association between air pollution and mortality and EHVs for cardiovascular diseases in Beijing showed the same results. There may be some co-linearity between $\mathrm{SO}_{2}$ and $\mathrm{NO}_{2}$ (Figure 1 and Table 2).

Studies have examined the potential biological mechanisms that help explain the effects of $\mathrm{SO}_{2}$ and

Table 1 Summary statistics of daily air pollutants, weather condition and emergency hospital visits for hypertension in Beijing, 2007

\begin{tabular}{|c|c|c|c|c|c|c|c|}
\hline & Minimum & $25 \%$ & $50 \%$ & $75 \%$ & Maximum & Mean & SD \\
\hline $\mathrm{SO}_{2}\left(\mu \mathrm{g} / \mathrm{m}^{3}\right)$ & 6.0 & 15.0 & 26.0 & 64.0 & 247.5 & 47.3 & 48.6 \\
\hline $\mathrm{NO}_{2}\left(\mu \mathrm{g} / \mathrm{m}^{3}\right)$ & 17.6 & 51.2 & 64.0 & 78.4 & 150.4 & 66.6 & 22.8 \\
\hline $\mathrm{PM}_{10}\left(\mu \mathrm{g} / \mathrm{m}^{3}\right)$ & 15.0 & 96.0 & 140.0 & 184.0 & 600.0 & 149.3 & 85.7 \\
\hline Temperature $\left({ }^{\circ} \mathrm{C}\right)$ & -6.1 & 3.7 & 14.5 & 25.0 & 30.7 & 14.1 & 10.7 \\
\hline Humidity (\%) & 15.0 & 37.0 & 54.0 & 74.0 & 97.0 & 54.2 & 20.9 \\
\hline EHVs & 0 & 2 & 4 & 5 & 19 & 4.1 & 0.1 \\
\hline
\end{tabular}



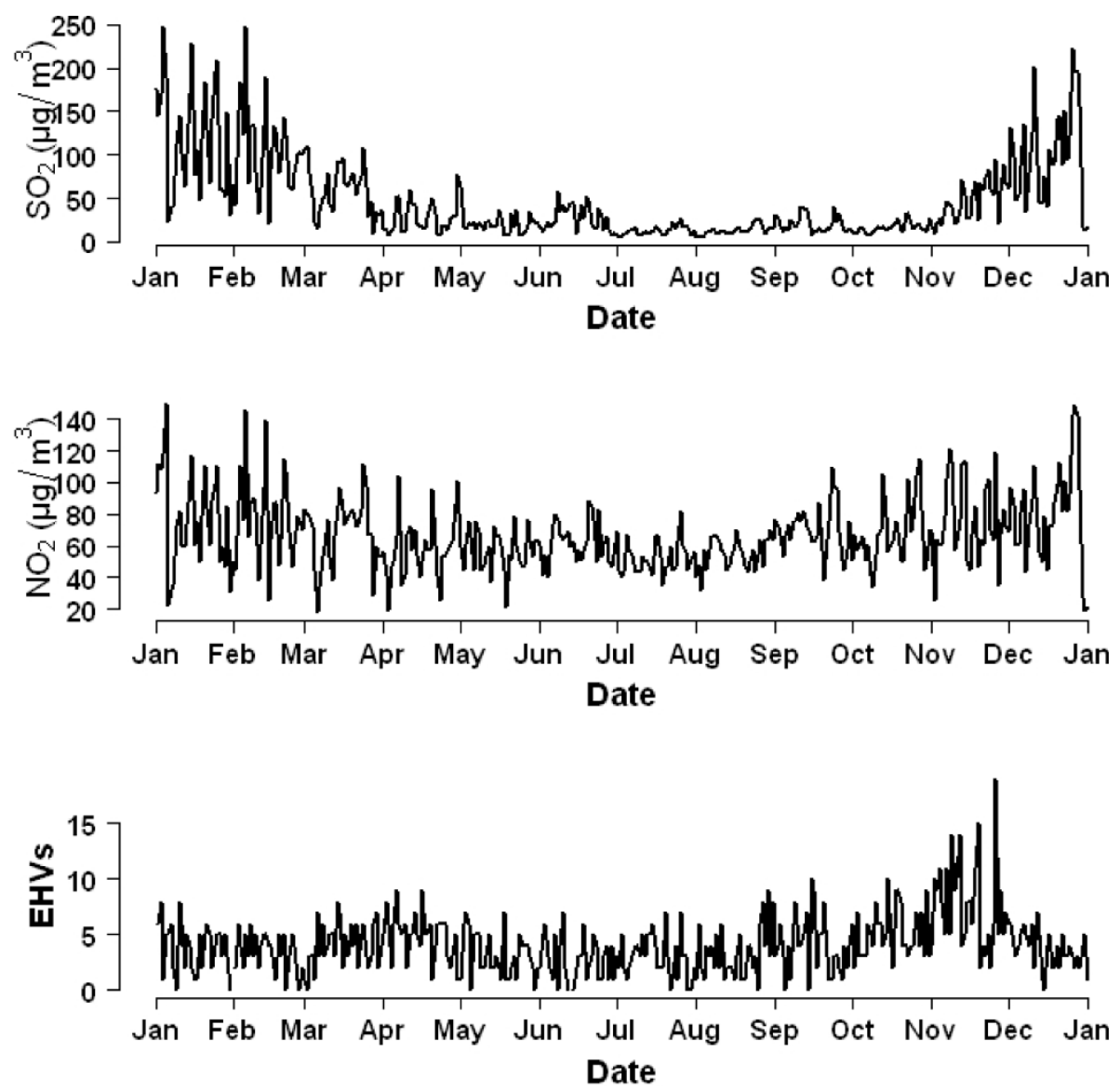

Figure 1 The time series of daily mean concentrations of gaseous air pollutants and number of emergency hospital visits for hypertension in Beijing during 2007.

$\mathrm{NO}_{2}$ on the cardiovascular system. As ambient $\mathrm{SO}_{2}$ concentrations rise, the $\mathrm{SO}_{2}$ concentration in blood and other tissues of the body increase [30]. When $\mathrm{SO}_{2}$ is inhaled the lipid peroxidation level in mice is raised. $\mathrm{SO}_{2}$ at all tested concentrations significantly decreased activities of superoxide dismutase in mice of both sexes, as well as that of glutathione peroxidase from male mice [31].

Some studies suggest that elevated levels of $\mathrm{NO}_{2}$ could increase the number of EHVs for cardiovascular disease $[5,6]$. Studies on the biological mechanism found that increased $\mathrm{NO}_{2}$ is associated with increased plasma

Table 2 Spearman's correlations between daily air pollutants and weather conditions in Beijing 2007

\begin{tabular}{lllll}
\hline & $\mathbf{P M}_{\mathbf{1 0}}$ & $\mathbf{S O}_{\mathbf{2}}$ & $\mathbf{N O}_{\mathbf{2}}$ & Temperature \\
\hline $\mathrm{SO}_{2}$ & $0.46^{a}$ & & & \\
\hline $\mathrm{NO}_{2}$ & $0.64^{a}$ & $0.65^{a}$ & & \\
\hline Temperature & 0.04 & $-0.68^{a}$ & $-0.28^{a}$ & \\
\hline Humidity & $0.28^{a}$ & $-0.12^{a}$ & $0.25^{a}$ & $0.21^{a}$ \\
\hline$a \mathrm{P}<0.05$. & & & &
\end{tabular}

fibrinogen, ventricular arrhythmia and ventricular tachycardia [32-34]. However, recently, Langrish et al. [35] found that inhalation of $\mathrm{NO}_{2}$ did not impair vascular vasomotor or fibrinolytic function in man.

Previous studies found that gaseous air pollutants have adverse effects on heart rate variability (HRV) which reflects cardiac autonomic function. Min et al. [36] measured HRV among community residents in Korea to study the effects of $\mathrm{PM}_{10}, \mathrm{SO}_{2}$, and $\mathrm{NO}_{2}$ on cardiac autonomic function, and found that exposure to $\mathrm{PM}_{10}$, $\mathrm{SO}_{2}$, and $\mathrm{NO}_{2}$ resulted in reduced $\mathrm{HRV}$, significant decreases in the standard deviation of the normal to normal interval (SDNN) and low frequency (LF) domain effect, and the effect was sustained for twelve hours. Routledge et al. [37] found that $\mathrm{SO}_{2}$ exposure resulted in a significant reduction in HRV markers of cardiac vagal control at four hours in healthy people, but no changes were found in patients with stable angina. de Paula Santos et al. [19] observed that an inter-quartile range increase of $9.6 \mu \mathrm{g} / \mathrm{m}^{3}$ in level of $\mathrm{SO}_{2}$ was negatively associated with SDNN of $-7.93 \mathrm{~ms}$ (95\% CI: -15.3 , - 0.6). Chan et al. [38] carried out a panel study to 

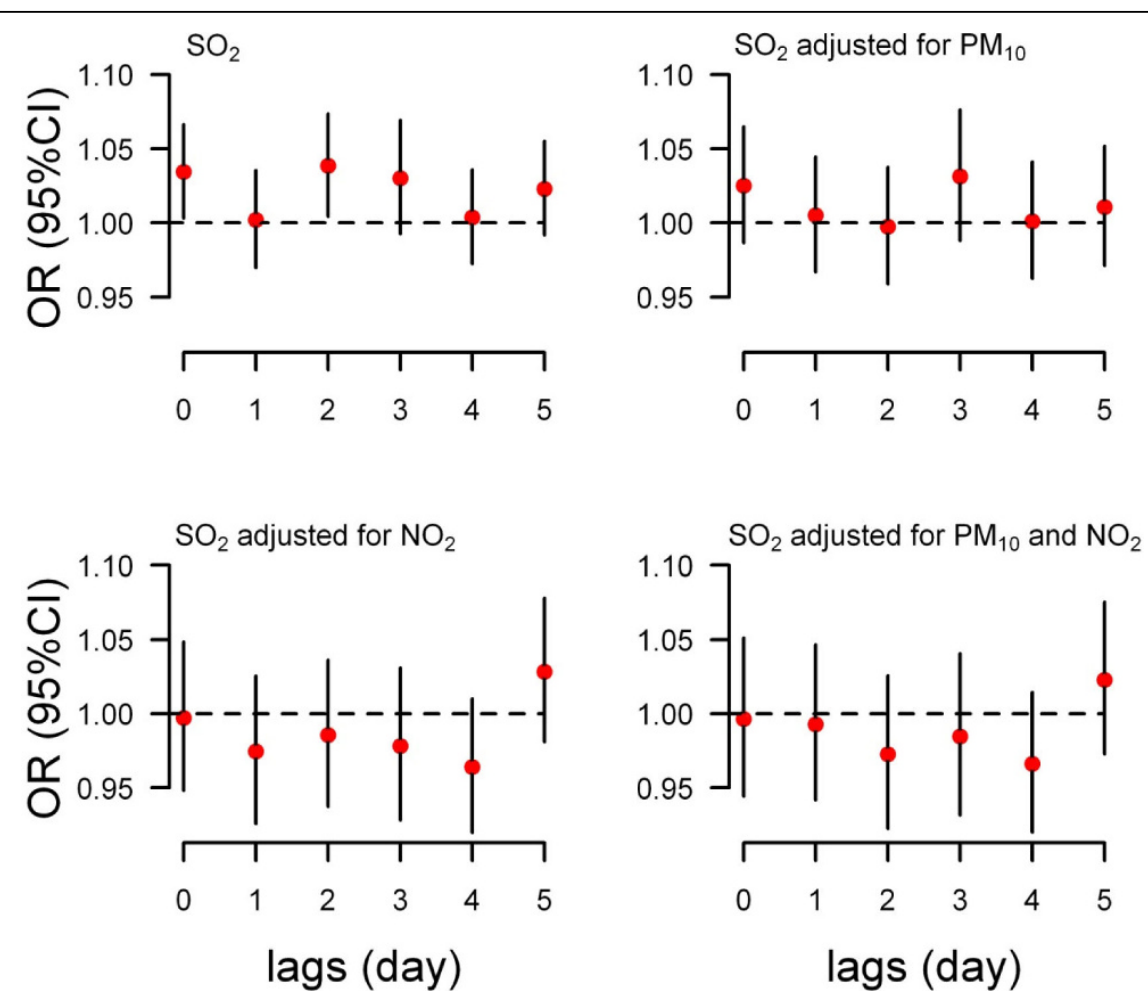

Figure 2 The association between a $10 \mathrm{ug} / \mathrm{m}^{3}$ increase in $\mathrm{SO}_{2}$ and daily emergency hospital visits for hypertension at lag days 0 to 5 in single pollutant and multiple pollutants models (time-stratified case-crossover controlling temperature and relative humidity).
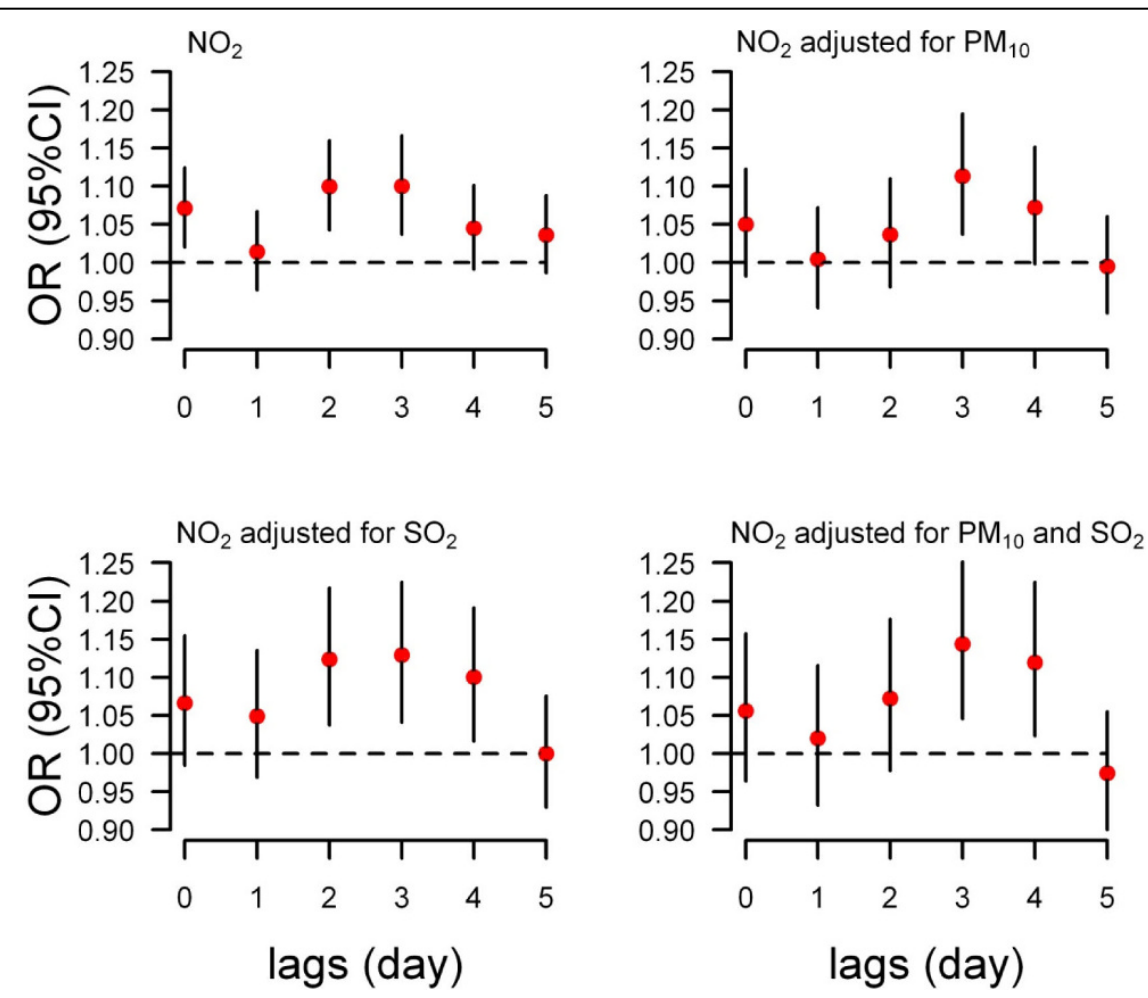

Figure 3 The association between a $10 \mathrm{ug} / \mathrm{m}^{3}$ increase in $\mathrm{NO}_{2}$ and daily emergency hospital visits for hypertension at lag days 0 to 5 in single pollutant and multiple pollutants models (time-stratified case-crossover controlling temperature and relative humidity). 
examine the association between $\mathrm{NO}_{2}$ and HRV in a susceptible population with coronary heart disease (CHD) or more than one major CHD risk factor, and found that an increase of $10 \mathrm{ppb}$ in $\mathrm{NO}_{2}$ was associated with 1.5-2.4\% decreases in SDNN, and for each $10 \mathrm{ppb}$ increase in $\mathrm{NO}_{2}$ the $\mathrm{LF}$ was decreased by $2.2-2.5 \%$.

Much research has been carried out to look at the influence of gaseous air pollution on mortality and morbidity for cardiovascular disease and shown that the increased concentrations of gaseous air pollution can impact on population health. Kan and Chen [39] applied a case-crossover to evaluate the relation between air pollution and daily mortality in Shanghai. The results showed that an increase of $10 \mu \mathrm{g} / \mathrm{m}^{3}$ in the levels of $\mathrm{SO}_{2}$ and $\mathrm{NO}_{2}$ had a relative risk of 1.017 (95\% CI: 1.009-1.026) and 1.024 (95\% CI: 1.011-1.036) for cardiovascular mortality. D'Ippoliti et al. [10] conducted a time-stratified case-crossover to explore the relationship between urban air pollutants and hospital admissions for acute myocardial infarction in Rome, and showed that each $10 \mu \mathrm{g} / \mathrm{m}^{3}$ increase of $\mathrm{NO}_{2}$ was associated with a relative risk of 1.026 (95\% CI: 1.002-1.052) for hospital admissions for acute myocardial infarction. Grazuleviciene et al. [40] carried out a population-based casecontrol study among men aged 25-64 years residing in Kaunas, to explore the relationship between long-term exposure to $\mathrm{NO}_{2}$ and myocardial infarction. Results suggested that urban $\mathrm{NO}_{2}$ pollution increased the risk of myocardial infarction.

This study has three strengths. Firstly, to our knowledge, it is the first epidemiological study which has specifically explored the relationship between gaseous air pollution and EHVs for hypertension. Secondly, a relative large sample size was used, with a considerable

\section{Table 3 Odds ratios for daily emergency hospital visits for hypertension for a $10 \mu \mathrm{g} / \mathrm{m}^{3}$ increase in air pollutants (Results from a time-stratified case-crossover for single pollutant and multiple pollutants models) ${ }^{a}$}

\begin{tabular}{llll}
\hline Air pollutants & OR & \multicolumn{2}{l}{$\mathbf{9 5 \%} \mathrm{Cl}$} \\
\cline { 2 - 4 } & & lower & upper \\
\hline $\mathrm{SO}_{2}$ & $1.037^{b}$ & 1.004 & 1.071 \\
\hline$+\mathrm{PM}_{10}$ & 1.025 & 0.987 & 1.065 \\
\hline$+\mathrm{NO}_{2}$ & 0.997 & 0.949 & 1.048 \\
\hline$+\mathrm{PM}_{10}+\mathrm{NO}_{2}$ & 0.997 & 0.945 & 1.051 \\
\hline $\mathrm{NO}_{2}$ & $1.101^{b}$ & 1.038 & 1.168 \\
\hline$+\mathrm{PM}_{10}$ & $1.114^{b}$ & 1.037 & 1.195 \\
\hline$+\mathrm{SO}_{2}$ & $1.130^{b}$ & 1.041 & 1.225 \\
\hline$+\mathrm{PM}_{10}+\mathrm{SO}_{2}$ & $1.144^{b}$ & 1.046 & 1.251
\end{tabular}

${ }^{a}$ ORs of $\mathrm{SO}_{2}$ are at lag 0 day; $\mathrm{ORs}$ of $\mathrm{NO}_{2}$ are at lag 3 day; OR: odds ratio; $\mathrm{Cl}$ : confidence interval;

${ }^{b} \mathrm{P}<0.05$. daily variance of exposure and outcomes. Finally, EHVs are a good indicator of the acute effects of air pollution, because when people in China with cardiovascular disease feel uncomfortable, the first choice they usually make is to visit the hospital emergency department.

This study also has some limitations. The cases were only selected from one hospital. Although the patients lived near the hospital, it still cannot control their hospital selection. Outdoor average concentrations of $\mathrm{PM}_{10}$, $\mathrm{SO}_{2}$ and $\mathrm{NO}_{2}$ were collected from fixed sites, but the data on individual exposure were unavailable. There might be misclassification bias for coding EHVs, because the diagnosis of EHVs for hypertension can never be $100 \%$ correct. Socioeconomic factors were not considered, as we could not get the patients' data on socioeconomics. The study was only conducted in the urban city of Beijing, and therefore the generalisability of the results is limited.

\section{Conclusion}

We found that elevated concentrations of gaseous air pollutants were associated with EHVs for hypertension in Beijing, China. The findings provide additional information about the health effects of air pollution, and may have implications for planning local environmental protection and public health interventions.

\section{Abbreviations}

EHVs: emergency hospital visits; SBP: systolic blood pressure; DBP: diastolic blood pressure; ICD10: International Classification of Disease, tenth revision; $\mathrm{SO}_{2}$ : sulfur dioxide; $\mathrm{NO}_{2}$ : nitrogen dioxide; $\mathrm{PM}_{10}$ : particulate matter less than $10 \mu \mathrm{m}$ in aerodynamic diameter; OR: odds ratio; Cl: confidence interval; HRV: heart rate variability; SDNN: standard deviation of the normal to normal interval; LF: low frequency; CHD: coronary heart disease; SD: standard deviation:

\section{Acknowledgements}

We thank the Medical Record Department of Peking University Third Hospital, the Beijing Municipal Environmental Monitoring Center, and China Meteorological Data Sharing Service System for providing data.

YMG is supported by the QUT Postgraduate Research Award (QUTPRA); SLT is supported by a NHMRC Research Fellowship (\#290515); this study is funded by the National Natural Science Foundation of China (\# 20637026).

\section{Author details}

${ }^{1}$ School of Public Health and Institute of Health and Biomedical Innovation, Queensland University of Technology, Kelvin Grove, Brisbane, Queensland 4059, Australia. ${ }^{2}$ Department of Child and Maternal Health and Institute of Child and Adolescent Health, Peking University School of Public Health, Beijing 100191, PR China. ${ }^{3}$ Department of Environmental Pollution and Health, Chinese Research Academy of Environmental Sciences, Beijing 100012, PR China. ${ }^{4}$ Department of Occupational and Environmental Health, Peking University School of Public Health, Beijing 100191, PR China.

\section{Authors' contributions}

YMG conceived and coordinated the study, performed data analysis and drafted the manuscript; SLT and SSL contributed to study design, reviewed and edited the manuscript; AGB contributed to statistical analysis, reviewed and edited the manuscript; WWY and YSZ contributed to review and edit the manuscript. XCP provided air pollution information and health data, and edited the manuscript; All authors have read and approved the final manuscript. 


\section{Competing interests}

The authors declare that they have no competing interests.

Received: 10 August 2010 Accepted: 5 October 2010

Published: 5 October 2010

\section{References}

1. Guo Y, Jia Y, Pan X, Liu L, Wichmann HE: The association between fine particulate air pollution and hospital emergency room visits for cardiovascular diseases in Beijing, China. Sci Total Environ 2009, 407:4826-4830

2. Simkhovich BZ, Kleinman MT, Kloner RA: Particulate air pollution and coronary heart disease. Curr Opin Cardiol 2009, 24:604-609.

3. Oudin A, Stroh E, Stromberg U, Jakobsson K, Bjork J: Long-term exposure to air pollution and hospital admissions for ischemic stroke. A registerbased case-control study using modelled $\mathrm{NO}(\mathrm{x})$ as exposure proxy. $B M C$ Public Health 2009, 9:301.

4. Halonen Jl, Lanki T, Yli-Tuomi T, Tiittanen P, Kulmala M, Pekkanen J: Particulate air pollution and acute cardiorespiratory hospital admissions and mortality among the elderly. Epidemiology 2009, 20:143-153.

5. Santos UP, Terra-Filho M, Lin CA, Pereira LA, Vieira TC, Saldiva PH, Braga AL: Cardiac arrhythmia emergency room visits and environmental air pollution in Sao Paulo, Brazil. J Epidemiol Community Health 2008, 62:267-272.

6. Szyszkowicz M: Ambient air pollution and daily emergency department visits for ischemic stroke in Edmonton, Canada. Int J Occup Med Environ Health 2008, 21:295-300.

7. Slaughter JC, Kim E, Sheppard L, Sullivan JH, Larson TV, Claiborn C: Association between particulate matter and emergency room visits, hospital admissions and mortality in Spokane, Washington. J Expo Anal Environ Epidemiol 2005, 15:153-159.

8. Kan H, Heiss G, Rose KM, Whitsel EA, Lurmann F, London SJ: Prospective analysis of traffic exposure as a risk factor for incident coronary heart disease: the Atherosclerosis Risk in Communities (ARIC) study. Environ Health Perspect 2008, 116:1463-1468

9. Chiu HF, Yang CY: Air pollution and emergency room visits for arrhythmias: are there potentially sensitive groups? I Toxicol Environ Health A 2009, 72:817-823.

10. D'Ippoliti D, Forastiere F, Ancona C, Agabiti N, Fusco D, Michelozzi P, Perucci CA: Air pollution and myocardial infarction in Rome: a casecrossover analysis. Epidemiology 2003, 14:528-535.

11. Lee IM, Tsai SS, Ho CK, Chiu HF, Wu TN, Yang CY: Air pollution and hospital admissions for congestive heart failure: are there potentially sensitive groups? Environ Res 2008, 108:348-353.

12. Wellenius GA, Schwartz J, Mittleman MA: Particulate air pollution and hospital admissions for congestive heart failure in seven United States cities. Am J Cardiol 2006, 97:404-408.

13. Guo $Y$, Tong $S$, Zhang $Y$, Barnett AG, Jia $Y$, Pan $X$ : The relationship between particulate air pollution and emergency hospital visits for hypertension in Beijing, China. Sci Total Environ 2010, 408:4446-4450.

14. Lopez AD, Mathers CD, Ezzati M, Jamison DT, Murray CJ: Global and regional burden of disease and risk factors, 2001: systematic analysis of population health data. Lancet 2006, 367:1747-1757.

15. Levy D, Larson MG, Vasan RS, Kannel WB, Ho KK: The progression from hypertension to congestive heart failure. JAMA 1996, 275:1557-1562

16. Wexler RK: Treatment of hypertension critical in reducing morbidity and mortality. J Am Board Fam Med 2007, 20:322.

17. Xu L, Wang S, Wang YX, Wang YS, Jonas JB: Prevalence of arterial hypertension in the adult population in rural and urban China: the Beijing eye study. Am J Hypertens 2008, 21:1117-1123.

18. Ibald-Mulli A, Stieber J, Wichmann HE, Koenig W, Peters A: Effects of air pollution on blood pressure: a population-based approach. Am J Public Health 2001, 91:571-577.

19. de Paula Santos U, Braga AL, Giorgi DM, Pereira LA, Grupi CJ, Lin CA Bussacos MA, Zanetta DM, do Nascimento Saldiva PH, Filho MT: Effects of air pollution on blood pressure and heart rate variability: a panel study of vehicular traffic controllers in the city of Sao Paulo, Brazil. Eur Heart $J$ 2005, 26:193-200.

20. Choi JH, Xu QS, Park SY, Kim JH, Hwang SS, Lee KH, Lee HJ, Hong YC Seasonal variation of effect of air pollution on blood pressure. $J$ Epidemiol Community Health 2007, 61:314-318.
21. Auchincloss AH, Diez Roux AV, Dvonch JT, Brown PL, Barr RG, Daviglus ML, Goff DC, Kaufman JD, O'Neill MS: Associations between recent exposure to ambient fine particulate matter and blood pressure in the Multiethnic Study of Atherosclerosis (MESA). Environ Health Perspect 2008 116:486-491

22. Lee JT, Schwartz J: Reanalysis of the effects of air pollution on daily mortality in Seoul, Korea: A case-crossover design. Environ Health Perspect 1999, 107:633-636.

23. Basu R, Dominici F, Samet JM: Temperature and mortality among the elderly in the United States: a comparison of epidemiologic methods. Epidemiology 2005, 16:58-66.

24. Armstrong B: Models for the relationship between ambient temperature and daily mortality. Epidemiology 2006, 17:624-631.

25. Braga AL, Zanobetti A, Schwartz J: The time course of weather-related deaths. Epidemiology 2001, 12:662-667.

26. Barnett AG, Dobson AJ: Analysing Seasonal Health Data. Berlin, Heidelberg: Springer 2010.

27. Barnett AG, Baker PJ, Dobson AJ: season: Analysing Seasonal Data R Functions. $R$ package version $0.2-52010$.

28. Meng $Z Y$, Ding $G A, X u X B, X u X D, Y u H Q$, Wang SF: Vertical distributions of $\mathrm{SO}(2)$ and $\mathrm{NO}(2)$ in the lower atmosphere in Beijing urban areas, China. Sci Total Environ 2008, 390:456-465.

29. Yang M, Pan X: Time-series analysis of air pollution and cardiovascular mortality in Beijing, China. J Environ Health 2008, 25:294-297.

30. Etlik O, Tomur A, Kutman MN, Yorukan S, Duman O: The effects of sulfur dioxide inhalation and antioxidant vitamins on red blood cell lipoperoxidation. Environ Res 1995, 71:25-28

31. Meng Z, Qin G, Zhang B, Geng H, Bai Q, Bai W, Liu C: Oxidative damage of sulfur dioxide inhalation on lungs and hearts of mice. Environ Res 2003, 93:285-292.

32. Pekkanen J, Brunner EJ, Anderson HR, Tiittanen P, Atkinson RW: Daily concentrations of air pollution and plasma fibrinogen in London. Occup Environ Med 2000, 57:818-822.

33. Peters A, Dockery DW, Muller JE, Mittleman MA: Increased particulate air pollution and the triggering of myocardial infarction. Circulation 2001 103:2810-2815.

34. Schwartz J: Air pollution and blood markers of cardiovascular risk. Environ Health Perspect 2001, 109:405-409.

35. Langrish JP, Lundback M, Barath S, Soderberg S, Mills NL, Newby DE, Sandstrom T, Blomberg A: Exposure to nitrogen dioxide is not associated with vascular dysfunction in man. Inhal Toxicol 2010, 22:192-198.

36. Min KB, Min JY, Cho SI, Paek D: The relationship between air pollutants and heart-rate variability among community residents in Korea. Inhal Toxicol 2008, 20:435-444.

37. Routledge HC, Manney S, Harrison RM, Ayres JG, Townend JN: Effect of inhaled sulphur dioxide and carbon particles on heart rate variability and markers of inflammation and coagulation in human subjects. Heart 2006, 92:220-227.

38. Chan CC, Chuang KJ, Su TC, Lin LY: Association between nitrogen dioxide and heart rate variability in a susceptible population. Eur J Cardiovasc Prev Rehabil 2005, 12:580-586.

39. Kan $\mathrm{H}$, Chen B: A case-crossover analysis of air pollution and daily mortality in Shanghai. J Occup Health 2003, 45:119-124.

40. Grazuleviciene R, Maroziene L, Dulskiene V, Malinauskiene V, Azaraviciene A, Laurinaviciene $D$, Jankauskiene $K$ : Exposure to urban nitrogen dioxide pollution and the risk of myocardial infarction. Scand J Work Environ Health 2004, 30:293-298.

doi:10.1186/1476-069X-9-57

Cite this article as: Guo et al:: Gaseous air pollution and emergency hospital visits for hypertension in Beijing, China: a time-stratified casecrossover study. Environmental Health 2010 9:57. 